\title{
Mucinous cystic neoplasm of the pancreas activated during pregnancy
}

\author{
Keisuke Kosumi, Hiroshi Takamori, Daisuke Hashimoto, Hiroshi Tanaka, Shinya Abe, Osamu Nakahara,
} Kei Horino and Hideo Baba*

\begin{abstract}
The characteristic histological feature of pancreatic mucinous cystic neoplasm (MCN) is ovarian-like stroma (OS) underlying the epithelium and existence of estrogen receptors and progesterone receptors in the nucleus of OS. We experienced a case of pancreatic MCN which was activated during pregnancy and confirmed the existence of estrogen receptors and progesterone receptors. In cases with potential factors for malignancy, surgical resection of MCN may be needed during pregnancy. On the other hand, in cases without these, as female sex hormones may have an influence on the behavior of pancreatic MCN during pregnancy, the timing of surgery should be decided on a case-by-case basis, taking into consideration the status of the malignancy, the stage of the pregnancy, and the condition of the mother and fetus.
\end{abstract}

Keywords: Mucinous cystic neoplasm; Pancreas; Activation; Pregnancy

\section{Background}

A mucinous cystic neoplasm $(\mathrm{MCN})$ is relatively rare, accounting for about $8 \%$ of resected cystic lesions of the pancreas [1]. And the characteristic histological feature is ovarian-like stroma (OS) underlying the epithelium [2]. As with an ovarian MCN, estrogen receptors (ER) and progesterone receptors $(\mathrm{PgR})$ are expressed in OS of pancreatic MCN [3], indicating that female sex hormones may have an influence on the behavior of pancreatic MCN, especially during pregnancy. We experienced a patient with pancreatic $\mathrm{MCN}$ which was activated during the pregnancy. Herein, we introduce the case, together with a literature review of MCN during pregnancy.

\section{Case presentation}

A 33-year-old woman who was 4 months pregnant complained of left back pain. Abdominal ultrasound revealed a $60-\mathrm{mm}$ cystic mass in the body and tail of the pancreas without a mural nodule or thickening of the wall (Figure 1a). The serum cancer antigen (CA) 19-9 level

\footnotetext{
* Correspondence: hdobaba@kumamoto-u.ac.jp

Department of Gastroenterological Surgery, Graduate School of Medical

Sciences, Kumamoto University, 1-1-1 Honjo, Chuo-ku, Kumamoto 860-8556, Japan
}

was elevated, at $92 \mathrm{U} / \mathrm{mL}$ (normal level is $<37 \mathrm{U} / \mathrm{mL}$ ), and then rapidly rose to $2,157 \mathrm{U} / \mathrm{mL}$ just before delivery.

The patient's antenatal course was uneventful, and the delivery was normal. After delivery, magnetic resonance imaging revealed that the cystic tumor was $76 \mathrm{~mm}$ in diameter, with a thickening septum seen on T2weighted imaging (Figure 1b). In addition, fluorodeoxyglucose positron emission tomography-computed tomography (FDG-PET/CT) showed an abnormally high uptake in part of the cystic tumor (Figure 1c). As FDG-PET/CT imaging indicated that malignancy could not be excluded, the patient underwent distal pancreatectomy on the 14th day after delivery (Figure 2a,b). Microscopically, the cyst wall was lined with benign mucinous columnar epithelium underlying OS (Figure 3a). In addition, immunohistochemical analysis showed that both ER and $\operatorname{PgR}$ were partially positive in the nucleus of OS (Figure 3b,c).

All pancreatic MCNs should be resected because they are considered as having malignant potential [4]. As increase in tumor size, mural nodules, and eggshell calcification predict malignant MCN [5], the ideal strategy is to remove the MCN surgically before these predictors develop. However, it is difficult to determine the best timing for surgery when pancreatic $\mathrm{MCN}$ is detected 

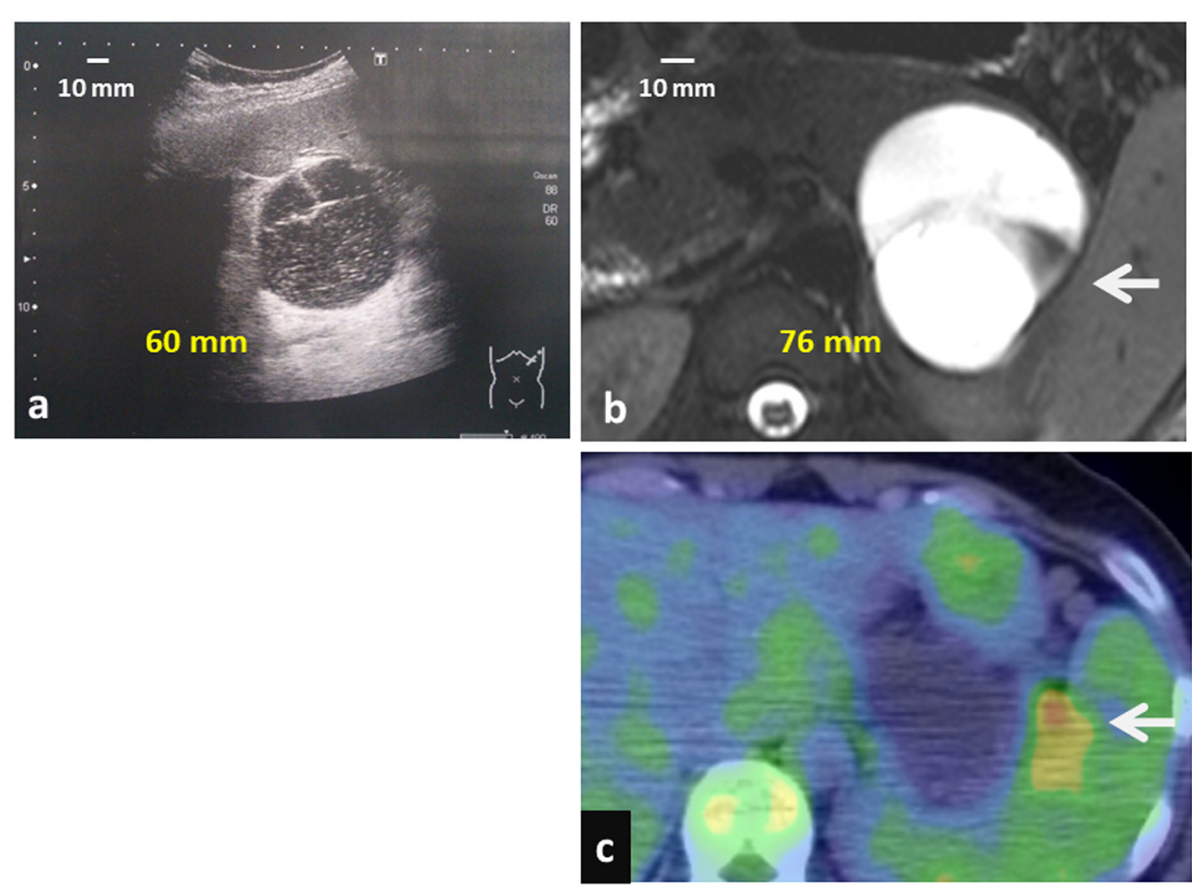

Figure 1 Imaging studies. (a) A 60-mm cystic mass was detected in the body and tail of the pancreas without a mural nodule or thickening of the wall by abdominal ultrasound (during the fourth month of gestation). (b) Magnetic resonance imaging (MRI) showed a $76 \times 69-\mathrm{mm}$ cystic tumor (arrow), in which the contents were hyperintense in T2-weighted imaging. There were septa in the tumor, and one part of it was thickened and enhanced. (c) Fluorodeoxyglucose positron emission tomography-computed tomography (FDG-PET/CT) showed high uptake (arrow) in part of the cystic tumor (SUVmax 3.03).

during pregnancy. There are several points of view. First, an accurate diagnosis of malignancy is difficult, especially for borderline cases. Second, it is necessary to consider the effects of surgery on the mother and the fetus.

We analyzed the clinical characteristics of MCNs detected during pregnancy according to data extracted from our case and previous reports [6-24], as well as our own experience (Table 1). In the reports reviewed, 12 patients underwent surgery during pregnancy, and neither miscarriage nor operation-related death occurred in any of the patients. Eight patients underwent operation after delivery. Regarding histopathological diagnosis, 14 patients were diagnosed with benign MCN, and 6 patients, 3 patients underwent operation during pregnancy and 3 patients after delivery, were diagnosed with adenocarcinoma. Among the six patients with adenocarcinoma, at least four patients were alive 1 year after resection.

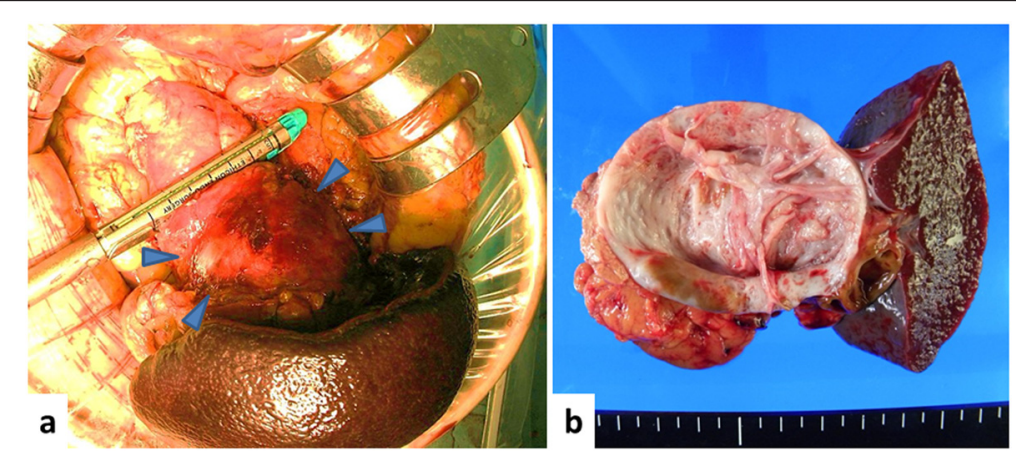

Figure 2 Intraoperative findings and macroscopic observations. (a) A smooth cystic tumor occupied the body and tail of pancreas (arrowheads indicating the tumor). Distal pancreatectomy was performed. (b) The cut surface of the tumor showing a large cyst without solid components. 


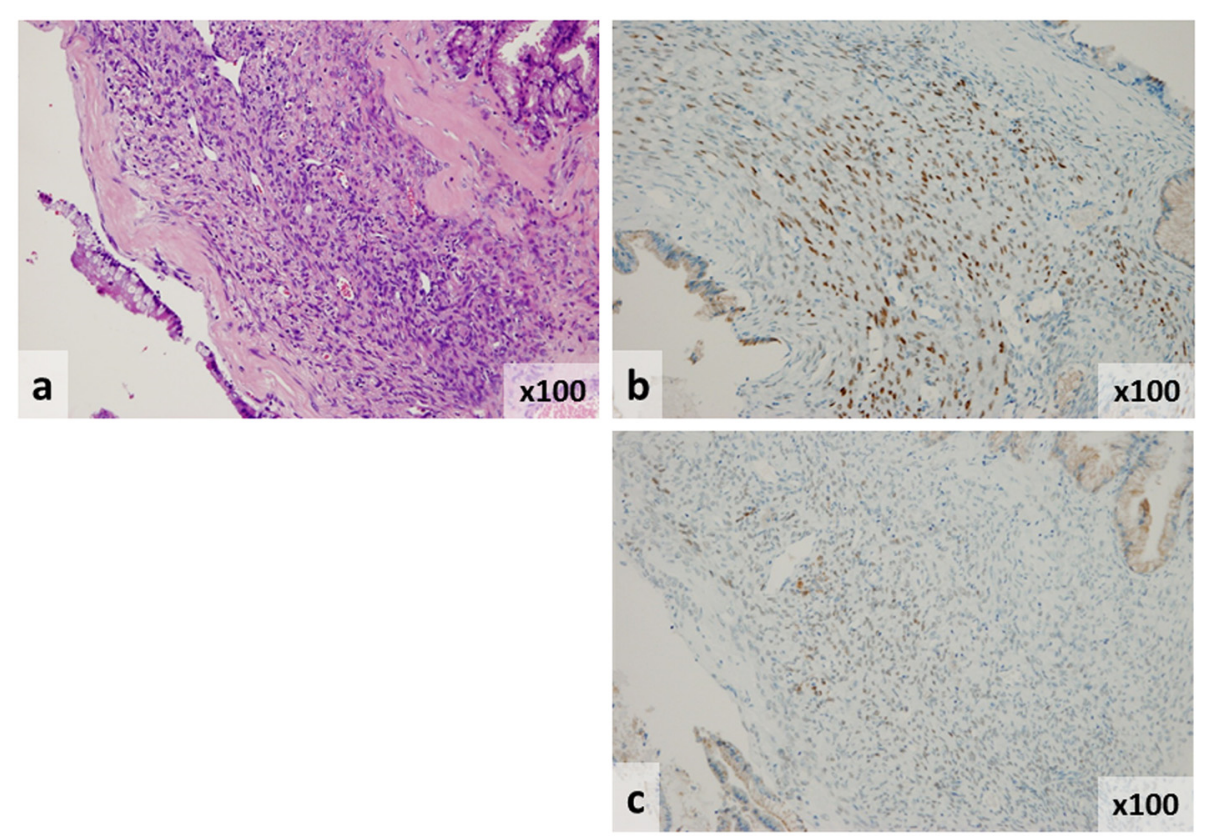

Figure 3 Analysis of pancreatic mucinous cystic adenoma by immunohistochemistry. (a) The cyst wall was lined with benign mucinous columnar epithelium underlying OS (Hematoxylin and eosin, $\times 100$ ). (b) Immunohistochemical studies showed partial positive staining for estrogen receptors in the nucleus of ovarian-type stroma (×100). (c) Immunohistochemical studies showed partial positive staining for progesterone receptors in the nucleus of ovarian-type stroma $(\times 100)$.

Importantly, in our case, we also confirmed the existence of ER and PgR. In addition, we confirmed rapid growth of MCN during pregnancy in nine patients, and at least seven patients of them showed positive staining for ER or PgR. Interestingly, Tanaka et al. reported a case of MCN developing during continuous hormone replacement therapy after hysterectomy. These findings suggested that the existence of ER and PgR might contribute to the activation of $\mathrm{MCN}$ during pregnancy.

Although the cutoff value of size and the mural nodule diameter for predicting malignancy has not been determined, it was generally reported that factors for predicting malignant $\mathrm{MCN}$ were large size and the existence of mural nodes [25]. In our case, we detected not only the two signs of malignant $\mathrm{MCN}$ but also an elevated CA19-9 level from 92 to 2,157 U/mL. A CA19-9 concentration $>37 \mathrm{U} / \mathrm{mL}$ had a positive predictive value of 95.7\% for potentially malignant lesions, but only showed a sensitivity of $35.8 \%$ [26]. In Table 1, five of the six patients showed the elevation of serum CA19-9 level, and the serum CA19-9 level of the patient with adenocarcinoma was remarkably higher. However, we could not find any relationships between the expression of hormone receptors and CA19-9 level, so further studies are necessary to validate the relationship between tumor markers and clinicopathological features including malignancy and hormone receptors.
In cases with potential factors for malignancy like large size and thickening septum, surgical resection of MCN may be needed. On the other hand, no findings of malignancy may enable the extension of surgical resection until delivery. In evaluating the possibility of malignant status of a MCN, consideration must be given to the stage of pregnancy and the condition of the mother and the fetus, and the timing of surgery should be decided on a case-by-case basis. Moreover, in view of the existence of ER and PgR, careful observation is necessary concerning the growth and progression of $\mathrm{MCN}$.

\section{Conclusions}

In cases with potential factors for malignancy, surgical resection of $\mathrm{MCN}$ may be needed during pregnancy. On the other hand, in cases without these, as female sex hormones may have an influence on the behavior of pancreatic MCN during pregnancy, the timing of surgery should be decided on a case-by-case basis, taking into consideration the status of the malignancy, the stage of the pregnancy, and the condition of the mother and fetus.

\section{Consent}

Written informed consent was obtained from the patient for publication of this case report and any accompanying images. A copy of the written consent is available for review by the Editor-in-Chief of this journal. 
Table 1 Literatures review of clinical characteristics of mucinous cystic neoplasm during pregnancy

\begin{tabular}{|c|c|c|c|c|c|c|c|c|}
\hline Author [reference number] & Age & $\begin{array}{l}\text { Maximum diameter } \\
\text { of tumor }(\mathrm{cm})\end{array}$ & $\begin{array}{l}\text { Diameter of tumor } \\
\text { growth during } \\
\text { pregnancy }(\mathrm{mm})\end{array}$ & CA19-9 (U/mL) & Timing of operation & Histological diagnosis & $\mathrm{ER} / \mathrm{PgR}$ & Prognosis (years) \\
\hline Smithers [6] & 33 & 10 & NA & NA & During pregnancy & Adenocarcinoma & NA & NA \\
\hline Baiocchi [7] & 29 & NA & NA & NA & After delivery & Adenocarcinoma & NA & Alive (2) \\
\hline Olsen [8] & 25 & 5 & 0 & NA & During pregnancy & Benign & NA & \\
\hline Ganepola [9] & 37 & 12 & 65 & NA & During pregnancy & Benign & $+/+$ & \\
\hline Kato [10] & 33 & 22 & + & NA & During pregnancy & Benign & $+/+$ & \\
\hline Matsunaga [11] & 28 & 20 & + & NA & During pregnancy & Adenocarcinoma & $-1+$ & NA \\
\hline Fernandez [12] & 26 & 15 & NA & NA & During pregnancy & Benign & NA & \\
\hline Herring [13] & 34 & 20 & 80 & NA & During pregnancy & Adenocarcinoma & $+/+$ & Alive (NA) \\
\hline Ozden [14] & 32 & 15 & NA & NA & After delivery (emergency cesarean) & Adenocarcinoma & $-1-$ & Alive (1) \\
\hline Ishikawa [15] & 33 & 18 & 60 & NA & After delivery & Benign & $-1-$ & \\
\hline Ikuta [16] & 30 & 18 & NA & Normal & After delivery (abortion) & Benign & $+/+$ & \\
\hline Hakamada [17] & 38 & 14 & 40 & NA & During pregnancy & Benign & $\mathrm{NA} /+$ & \\
\hline Wiseman [18] & 32 & 15 & NA & NA & During pregnancy & Benign & $+/+$ & \\
\hline Brown [19] & 38 & 10 & NA & NA & During pregnancy & Benign & NA & \\
\hline Shirakawa [20] & 34 & 19 & 0 & Elevated & After delivery & Benign & $+/+$ & \\
\hline Asciutti [21] & 31 & 8 & 65 & 214 & After delivery & Benign & NA & \\
\hline Nagamura [22] & 32 & 11 & NA & 4,750 & After delivery (emergency cesarean) & Adenocarcinoma & $-/+$ & Alive (3) \\
\hline Boyd CA [23] & 21 & 17.2 & 0 & NA & During pregnancy & Benign & NA & \\
\hline Tsuda [24] & 28 & 14 & 10 & 10 & During pregnancy & Benign & $+/+$ & \\
\hline Present case & 33 & 7.6 & 16 & 2,157 & After delivery & Benign & $+/+$ & \\
\hline
\end{tabular}

CA19-9, cancer antigen 19-9; ER, estrogen receptor; NA, not available; PgR, progesterone receptor. 


\section{Abbreviations}

CA19-9: cancer antigen 19-9; ER: estrogen receptors; FDG-PET/CT:

fluorodeoxyglucose positron emission tomography-computed tomography; MCN: mucinous cystic neoplasm; MRl: magnetic resonance imaging; NA: not available; OS: ovarian-like stroma; PgR: progesterone receptors;

SUVmax: maximum standardized uptake value.

\section{Competing interests}

The authors declare that they have no competing interests.

\section{Authors' contributions}

KK carried out the acquisition of data and drafted the manuscript. HT and $\mathrm{DH}$ involved in drafting the manuscript. HT, SA, ON, and $\mathrm{KH}$ carried out the acquisition of data. HB has given final approval of the version to be published. All authors read and approved the final manuscript.

\section{Acknowledgements}

No funding was received for this study.

We thank Marilyn Carlson who provided medical writing services on behalf of Forte Inc.

Received: 18 August 2014 Accepted: 22 December 2014 Published online: 10 February 2015

\section{References}

1. Kosmahl M, Pauser U, Peters K, Sipos B, Luttges J, Kremer B, et al. Cystic neoplasms of the pancreas and tumor-like lesions with cystic features: a review of 418 cases and a classification proposal. Virchows Arch. 2004;445(2):168-78. doi:10.1007/s00428-004-1043-z.

2. Compagno J, Oertel JE. Mucinous cystic neoplasms of the pancreas with overt and latent malignancy (cystadenocarcinoma and cystadenoma). A clinicopathologic study of 41 cases. Am J Clin Pathol. 1978;69(6):573-80.

3. Izumo A, Yamaguchi K, Eguchi T, Nishiyama K, Yamamoto H, Yonemasu H, et al. Mucinous cystic tumor of the pancreas: immunohistochemical assessment of "ovarian-type stroma". Oncol Rep. 2003;10(3):515-25.

4. Tanaka M, Fernandez-del Castillo C, Adsay V, Chari S, Falconi M, Jang JY, et al. International consensus guidelines 2012 for the management of IPMN and MCN of the pancreas. Pancreatology. 2012;12(3):183-97. doi:10.1016/j.pan.2012.04.004.

5. Warshaw AL, Compton CC, Lewandrowski K, Cardenosa G, Mueller PR. Cystic tumors of the pancreas. New clinical, radiologic, and pathologic observations in 67 patients. Ann Surg. 1990;212(4):432-43. discussion 44-5.

6. Smithers BM, Welch C, Goodall P. Cystadenocarcinoma of the pancreas presenting in pregnancy. Br J Surg. 1986;73(7):591.

7. Baiocchi C, Landonio G, Majno M, Minola E, Scanzi F, Ghislandi E. Pancreatic cystadenocarcinoma and pregnancy: a case report. Tumori. 1990;76(3):294-5.

8. Olsen M, Greer M, Feintuch T. Pancreatic mucinous cystadenoma during pregnancy. Am J Gynecol Health. 1993;4:27-30.

9. Ganepola GA, Gritsman AY, Asimakopulos N, Yiengpruksawan A. Are pancreatic tumors hormone dependent?: A case report of unusual, rapidly growing pancreatic tumor during pregnancy, its possible relationship to female sex hormones, and review of the literature. Am Surg. 1999:65(2):105-11.

10. Kato M, Kubota K, Kita J, Shimoda M, Rokkaku K, Inaba N, et al. Huge mucinous cystadenoma of the pancreas developing during pregnancy: a case report. Pancreas. 2005;30(2):186-8.

11. Matsunaga T, Kato T, Tamura M. A case of rapidly growing pancreatic cystadenocarcinoma during pregnancy. Obstet Gynecol Pract. 2005:54(9):1483-6.

12. Lopez-Tomassetti Fernandez EM, Martin Malagon A, Arteaga Gonzalez I, Muniz Montes JR, Diaz Luis H, Gonzalez Hermoso F, et al. Mucinous cystic neoplasm of the pancreas during pregnancy: the importance of proper management. J Hepato-Biliary-Pancreat Surg. 2005;12(6):494-7. doi:10.1007/s00534-005-1005-0.

13. Herring AA, Graubard MB, Gan SI, Schwaitzberg SD. Mucinous cystadenocarcinoma of the pancreas during pregnancy. Pancreas. 2007;34(4):470-3. doi:10.1097/mpa.0b013e31803799d8.

14. Ozden S, Haliloglu B, Ilter E, Akin FT, Kebudi A, Peker O. An extremely rare cause of acute abdomen in pregnancy: ruptured pancreatic mucinous cystadenocarcinoma. Pancreas. 2007;34(4):474-6. doi:10.1097/mpa.0b013e31803799ee.

15. Ishikawa K, Hirashita T, Kinoshita H, Kitano M, Matsuo S, Matsumata T, et al. Large mucinous cystadenoma of the pancreas during pregnancy: report of a case. Surg Today. 2007:37(11):1013-7. doi:10.1007/s00595-007-3500-1.

16. Ikuta S, Aihara T, Yasui C, lida H, Yanagi H, Mitsunobu M, et al. Large mucinous cystic neoplasm of the pancreas associated with pregnancy. World J Gastroenterol. 2008;14(47):7252-5.

17. Hakamada K, Miura T, Kimura A, Nara M, Toyoki Y, Narumi S, et al. Anaplastic carcinoma associated with a mucinous cystic neoplasm of the pancreas during pregnancy: report of a case and a review of the literature. World J Gastroenterol. 2008;14(1):132-5.

18. Wiseman JE, Yamamoto M, Nguyen TD, Bonadio J, Imagawa DK. Cystic pancreatic neoplasm in pregnancy: a case report and review of the literature. Arch Surg. 2008;143(1):84-6. doi:10.1001/archsurg.2007.4.

19. Brown TH, Menon VS, Richards DG, Griffiths AP. Gastrointestinal bleeding in a pregnant woman: mucinous cystic neoplasm of pancreas mimicking gastrointestinal stromal tumor of stomach. J Hepato-Biliary-Pancreat Surg. 2009;16(5):681-3. doi:10.1007/s00534-009-0159-6.

20. Shirakawa S, Matsumoto I, Nakayama S, Mukubo H, Toyama H, Shinzeki M, et al. Mucinous cystic neoplasm of the pancreas associated with pregnancy: report of two cases. Nihon Shokakibyo Gakkai Zasshi. 2010;107:1828-34.

21. Asciutti S, Kanninen TT, Clerici G, Nardi E, Castellani D, Di Renzo GC, et al. Acute pancreatitis with a mucinous cystoadenoma of the pancreas in pregnancy. Anticancer Res. 2010;30(3):1025-8.

22. Naganuma S, Honda K, Noriki S, Kimura S, Murakami M, Koneri K, et al. Ruptured mucinous cystic neoplasm with an associated invasive carcinoma of pancreatic head in a pregnant woman: report of a case and review of literature. Pathol Int. 2011;61(1):28-33. doi:10.1111/j.1440-1827.2010.02609.x.

23. Boyd CA, Benarroch-Gampel J, Kilic G, Kruse EJ, Weber SM, Riall TS. Pancreatic neoplasms in pregnancy: diagnosis, complications, and management. J Gastrointest Surg. 2012;16(5):1064-71. doi:10.1007/s11605-011-1797-y.

24. Tsuda H, Kotani T, Sumigama S, Mano Y, Shimoyama Y, Kikkawa F. Mucinous cystic neoplasm of the pancreas with severe dysplasia during pregnancy: case report and review of the literature. Taiwan J Obstet Gynecol. 2012;51(4):635-8. doi:10.1016/j.tjog.2012.09.022

25. Yamao K, Yanagisawa A, Takahashi K, Kimura W, Doi R, Fukushima N, et al. Clinicopathological features and prognosis of mucinous cystic neoplasm with ovarian-type stroma: a multi-institutional study of the Japan pancreas society. Pancreas. 2011;40(1):67-71. doi:10.1097/MPA.0b013e3181f749d3.

26. Fernandez-del Castillo C, Alsfasser G, Targarona J, Brugge WR, Warshaw AL. Serum CA 19-9 in the management of cystic lesions of the pancreas. Pancreas. 2006;32(2):220. doi:10.1097/01.mpa.0000202946.72493.74.

\section{Submit your manuscript to a SpringerOpen ${ }^{\odot}$ journal and benefit from:}

- Convenient online submission

- Rigorous peer review

- Immediate publication on acceptance

- Open access: articles freely available online

- High visibility within the field

- Retaining the copyright to your article

Submit your next manuscript at springeropen.com 